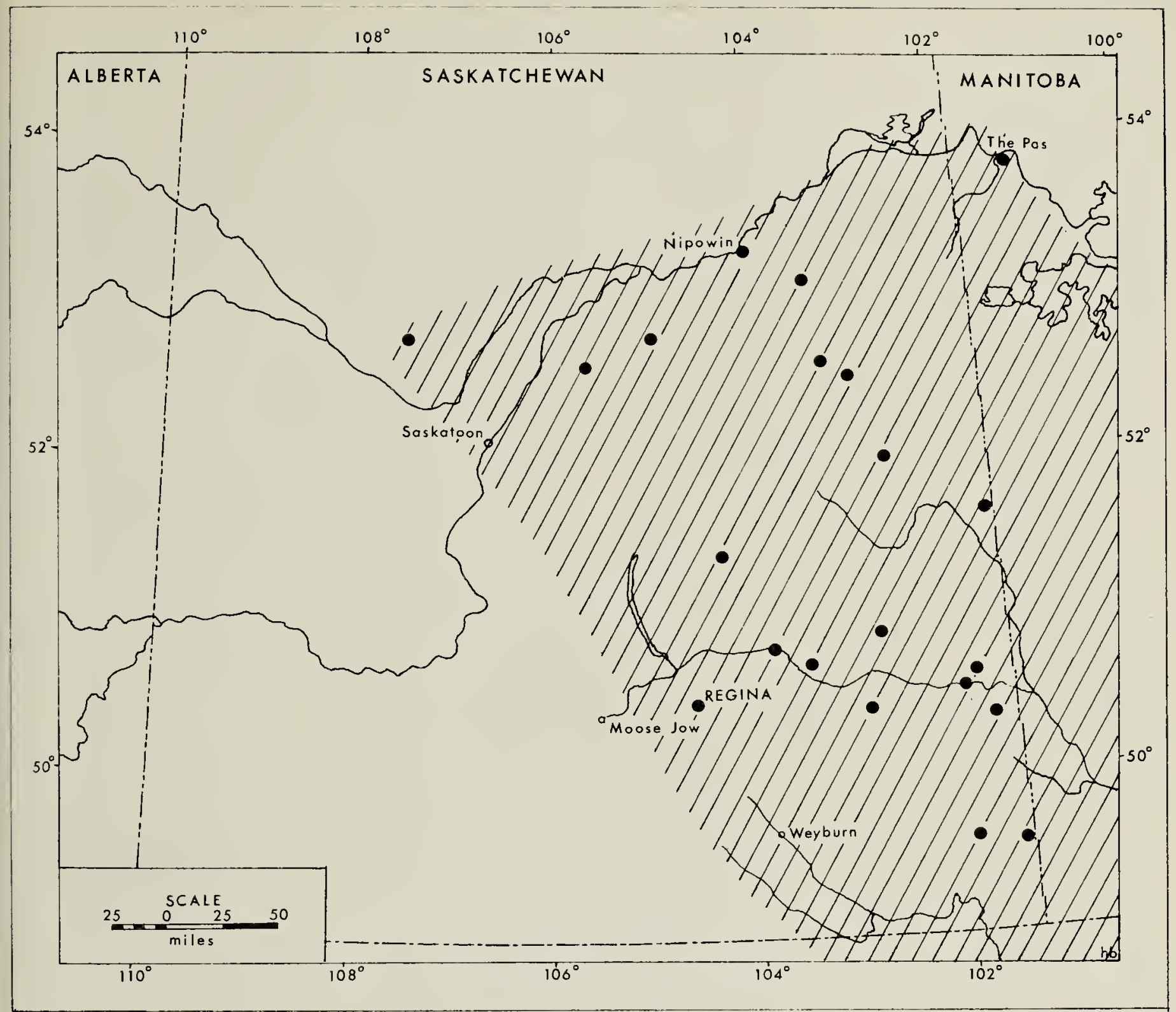

The distribution of the Short-tailed Shrew in Saskatchewan.

\title{
THE EXTENSION OF THE WESTERN SMOOTH GREEN SNAKE INTO SOUTH CENTRAL SASKATCHEWAN
}

\author{
by Dianne M. Secoy, University of Saskatchewan, Regina
}

On September 29, 1968, on a field trip to the badlands of Big Muddy Lake, we took a specimen of the Western Smooth Green Snake (Opheodrys $v$. vernalis Harlan). The snake was found in the grass in the bottom of one of the small valleys of the badlands to the south of Big Muddy Lake. At this time a specimen of Pituophis melanoleucas sayi was also taken.

The Western Smooth Green Snake has been reported previously only from the Qu'Appelle Valley and the region around North Portal in the southeastern portion of the province. This specimen was taken approximately 100 miles west of the North Portal area and 125 miles southwest of the Qu'Appelle Valley. However, since it was taken in prairie, the westward extension of the range constitutes no change in ecological habitat and may simply reflect a lack of extensive herpetological collecting. 